\begin{tabular}{cc}
\hline International Journal of Engineering \& Technology, $7(2.23)(2018) 21-23$ \\
SPC & Website: ww.sciencepubco.com/index.php/IJET \\
Research paper & Intional Journal of Engineering \& Technology \\
\hline
\end{tabular}

\title{
Influence of lignosulfonic acids on the formation of magnetoactive compound in the redox reaction of iron(II) with chromate-anion
}

\author{
Nikolay Yu. Kuzyakov ${ }^{1}$, Viacheslav A. Veshnyakov ${ }^{1}$, Yuriy G. Khabarov ${ }^{1 *}$, Galina V. Pankina ${ }^{2}$ \\ ${ }^{1}$ Northern (Arctic) Federal University, nab. Severnoi Dviny 17, Arkhangel'sk, Russia. \\ ${ }^{2}$ Lomonosov Moscow State University, Leninskie gory 1, Moscow, Russia \\ *Corresponding author E-mail: khabarov.yu@mail.ru
}

\begin{abstract}
Chromium and its compounds are widely used in various industries. Wastewater from industrial enterprises using chromium compounds are subject to complete disposal at treatment facilities. The possibility of synthesizing a magnetoactive compound by oxidizing part of $\mathrm{Fe}(\mathrm{II})$ cations with chromate-anions in the presence of lignosulfonates was investigated. The magnetic activity was measured on Gouy balance, magnetic characteristics were determined by the magnetic granulometry method. It has been shown that the interaction of Fe(II) cations with chromate-anions passes with the formation of an water soluble intermediate without redox transformations at $\mathrm{pH} 3.4$. Using method of the isomolar series, it was determined that the ratio of chromate-ions and Fe(II) cations in the intermediate is 1:2.33. The intermediate solution is stable for a long time. Synthesized magnetoactive compound samples are ferrimagnets. The use of lignosulfonate and the synthesis with heating can achieve a higher magnetic activity of magnetoactive compound. The optimal lignosulfonate consumption is $0.7 \mathrm{~g} / \mathrm{g} \mathrm{Fe}$.
\end{abstract}

Keywords: Chromate; Iron(II); Lignosulfonates; Magnetoactive compound; Complex.

\section{Introduction}

Chromium and its compounds are widely used in various industries. Wastewater from industrial enterprises using chromium compounds are subject to complete disposal at treatment facilities. The problem of increasing the efficiency of wastewater treatment from chromium(VI) compounds in connection with this is topical.

Electrochemical methods [1], sorption [2], extraction and biochemical methods [3] are used to neutralize liquid waste products containing chromium(VI). The reduction of chromium(VI) followed by precipitation of chromium(III) in the form of a water insoluble compound is important among the chemical methods for treating wastewater. For the conversion of chromium(VI) into chromium(III), organic and inorganic compounds with reducing properties are proposed.

A magnetoactive compounds (MCs) are formed as a result of the interaction of iron(II) cations with chromium(VI) compounds followed by condensation with an alkaline reagent. These include magnetite $\left(\mathrm{Fe}_{3} \mathrm{O}_{4}\right)$ and ferrites of certain metals of composition $\mathrm{MeFe}_{2} \mathrm{O}_{4}$. The great practical importance of MCs causes a constant interest in researching their properties and developing new methods of synthesis. Magnetite has catalytic properties [4], it can be used in the creation of materials intended for diagnosis and therapy [5], in the printing and in devices for magnetic recording of information [6], [7], [8], for wastewater treatment [9], in the neutralization of wastes in the oil and gas industry, for adsorption desulfurization [10], in the production of feed additives, in machine building, in the food industry, in the production of compo- sites, anodes, in the separation and purification of inorganic and organic compounds [11].

A large number of methods have been developed for synthesis of magnetite type MCs, the main ones being condensation methods from molecules and ions. Magnetite is usually synthesized using a condensation method based on the reaction taking place with the participation of $\mathrm{Fe}^{3+}$ and $\mathrm{Fe}^{2+}$ [12], taken in the ratio 2:1.

The shape, size, composition and properties of magnetite particles depend on the type of iron salt, the ratio of $\mathrm{Fe}^{2+} / \mathrm{Fe}^{3+}$ [13], the reaction temperature [14], $\mathrm{pH}$ [15], as well as the type of base and stirring rate [16], the presence of modifiers [17]. Synthesis methods based on the oxidation of part of iron(II) cations are less common.

Lignosulfonic acids (LSA) are formed from natural lignin during the sulfite pulping process. LSA, like other types of lignins, have an irregular chemical structure (Figure 1). LSA and their salts (LS) have polyelectrolytic and complexing properties and are able to dissolve in an aqueous medium over a wide $\mathrm{pH}$ range [18].

Initial and modified LS are used in the synthesis of magnetoactive compounds and ferrofluids with particles of a nanoscale range. Therefore, it was of interest to determine the effect of LS and the conditions for carrying out the synthesis on the properties of a magnetoactive compound obtained by the interaction of iron(II) ions with chromium(VI) compounds. 


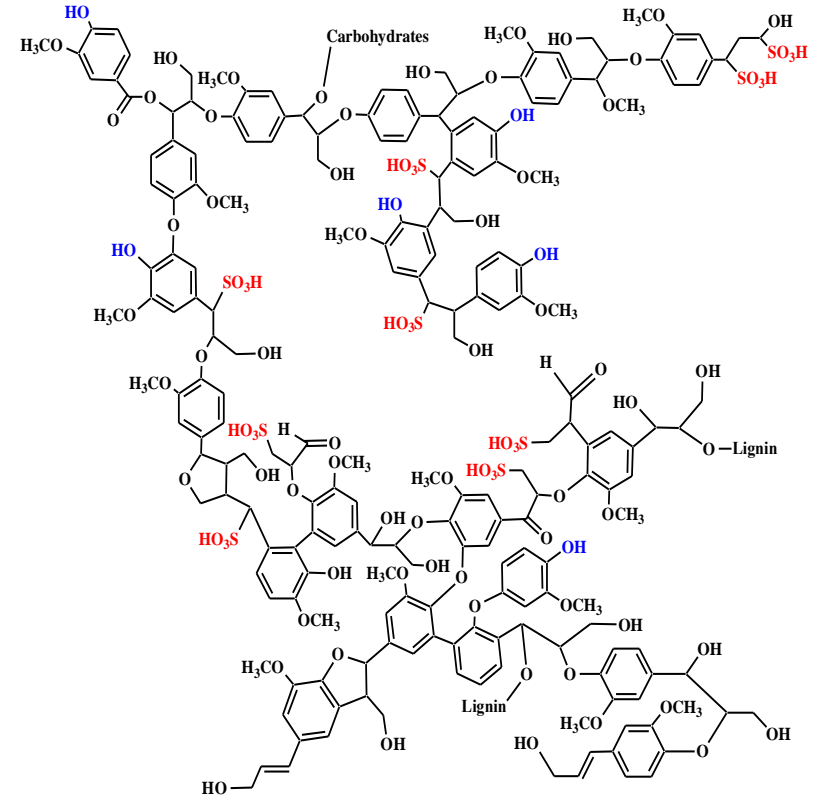

Fig. 1: A lignosulfonic acid macromolecule fragment

\section{Material and methods}

\subsection{Materials}

In the experiments the following commercial reagents were used: iron(II) sulphate heptahydrate, potassium chromate, potassium dichromate, glacial acetic acid, sodium hydroxide. Powdered sodium LS was obtained from industrial production sulphite cooking of spruce wood.

\subsection{Preparation of the magnetoactive compound}

To obtain the MC, the predetermined volume of a solution of the sodium LS (15.1 mg/mL), $1 \mathrm{~mL}$ of iron(II) sulphate solution (21.4 $\mathrm{mg} \mathrm{Fe} / \mathrm{mL}$ ), predetermined volume of a potassium chromate solution $(40 \mathrm{mg} / \mathrm{mL})$ and $10 \mathrm{~mL}$ of $2 \mathrm{M} \mathrm{NaOH}$ were added in the test tube. Condensation was carried out in a Lauda Alpha A12 thermostat at $25,40,50$ or $70{ }^{\circ} \mathrm{C}$.

\subsection{Methods}

The magnetic activity (MA, g) [19] of the formed precipitate was measured after the given time intervals. The magnetic characteristics of precipitates were measured by the magnetic granulometry method [20]. Redox potential and $\mathrm{pH}$ were measured with a Hanna HI $2211 \mathrm{pH} / \mathrm{ORP}$ Meter. UV-Vis spectra of solutions in acetate buffer with $\mathrm{pH} 3.4$ were recorded on a Shimadzu UV-Vis 1650pc spectrophotometer in the wavelength range $400 \ldots 700 \mathrm{~nm}$ in quartz cuvettes (pathlength $0.155 \mathrm{~mm}$ ).

\section{Results and discussion}

The formation of MC occurs when the iron(II) cations are partially oxidized by chromate-anions. Oxidizing properties of chromi$\mathrm{um}(\mathrm{VI})$ depend on the $\mathrm{pH}$ of the solution [21]. The oxidationreduction reaction is stepwise, in which the degree of oxidation of the chromium ion gradually decreases from +6 to +3 .

$\mathrm{MC}$ is formed due to the ferritization process including redox reaction and gradual dehydration of hydroxocomplexes. Fragment of complex taken part in dehydration due to the intramolecular electron redistribution are presented below:

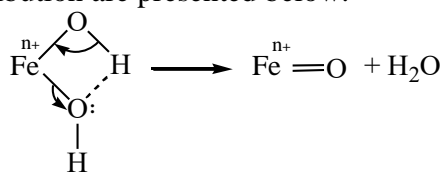

When a solution of lignosulfonates and iron(II) sulfate is mixed with a solution of potassium chromate, the UV-Vis spectrum changes so that the mixture spectrum of all components is not additive (Figure 2). The change of spectrum of the reaction mixture appears to be due to the formation of intermediate complexes.

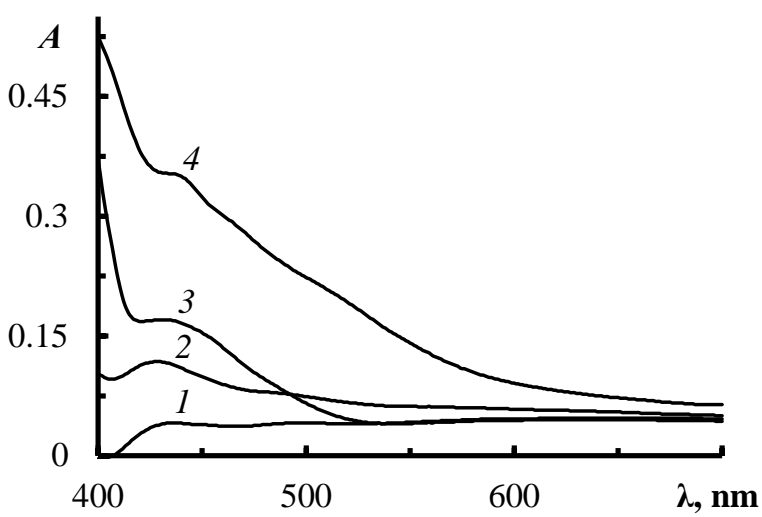

Fig. 2: UV-vis spectra of iron(II) sulfate (1), LS (2), potassium chromate (3) and their mixture (4) in acetate buffer solution with $\mathrm{pH} 3.4$ and quartz cuvettes (pathlength $0.155 \mathrm{~mm}$ )

The isomolar series method was used to determine the composition of the intermediate. The total concentration of iron(II) sulfate and potassium chromate was $0.52 \mathrm{M}$. The results of the experiment are shown in Figure 3.

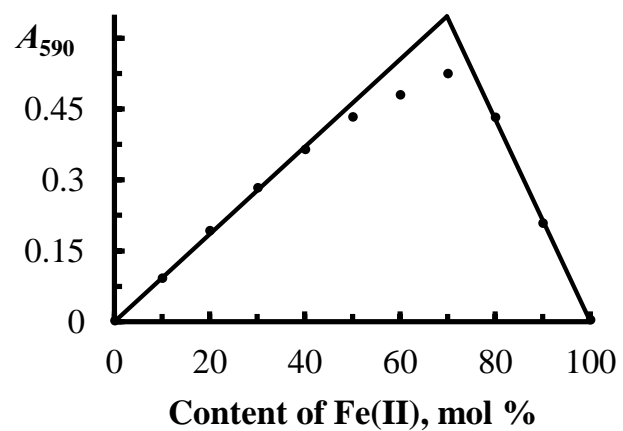

Fig. 3: Diagram "Relative content of Fe(II) - absorbance at 590 nm"

The composition determined from the coordinate of the point of intersection of the tangents corresponds to the molar ratio of chromate ions and iron(II) as 1:2.33.

The redox potential increases from 239 to $248 \mathrm{mV}$ during one day after mixing the solution of LS and iron(II) sulfate with a solution of potassium chromate (Figure 4). This indicates that the redox reactions during the formation of the intermediate complex are not significant.

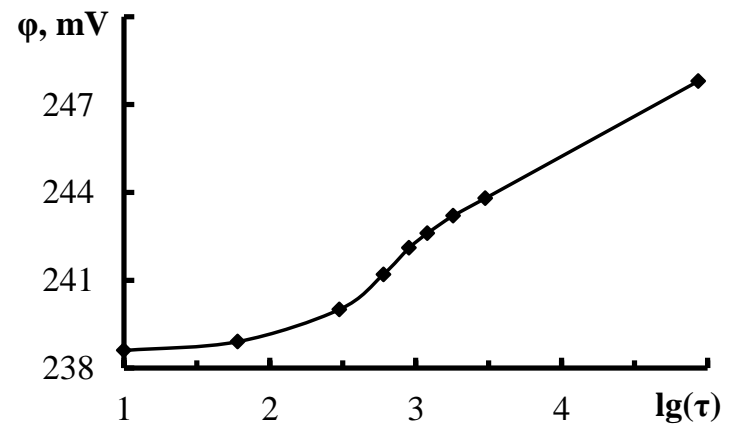

Fig 4: Dependence of redox potential $(\varphi, \mathrm{mV})$ of the reaction mixture on the duration of storage $(\tau, s)$

A magnetoactive compound is formed as a result of condensation when the reaction mixture was alkalinized. Theoretically, 2/3 of iron(II) cations are to oxidize for obtaining of magnetite, in this case the ratio of chromate-anion to iron(II) should be 1:4.5. Earlier it was experimentally shown that the ratio of chromate-anion to 
iron(II) 1:5.5 is optimal for obtaining a magnetoactive compound [22]. The magnetic activity of the precipitate released during alkalinization is gradually formed due to ferritization. This process depends on a number of factors, which include the reagent ratio and temperature.

Influence of the LS consumption and temperature on magnetic activity. The study of the properties of the product synthesized at $25,40,50,70{ }^{\circ} \mathrm{C}$ under conditions with a LS consumption in the range $0 \ldots 1.05 \mathrm{~g} \mathrm{LS} / \mathrm{g} \mathrm{Fe}$ and a constant molar ratio of chromateanions and iron(II) ions (1:5.5) showed that the presence of LS in the condensation of a magnetoactive compound has a significant effect on the properties of the product (Table 1).

Table 1: The effect of the LS consumption and the synthesis temperature on the magnetic activity of MC

\begin{tabular}{c|c|c|c|c}
\hline \multirow{2}{*}{$\begin{array}{c}\text { LS consumption } \\
(\mathrm{g} \mathrm{LS} / \mathrm{g} \mathrm{Fe})\end{array}$} & \multicolumn{4}{|c}{ MA (after $60 \mathrm{~min}), \mathrm{mg}$} \\
\cline { 2 - 5 } & $25^{\circ} \mathrm{C}$ & $40^{\circ} \mathrm{C}$ & $50^{\circ} \mathrm{C}$ & $70{ }^{\circ} \mathrm{C}$ \\
\hline 0 & 10 & 21 & 48 & 88 \\
0.35 & 64 & 126 & 206 & 247 \\
0.70 & 97 & 176 & 224 & 262 \\
1.05 & 63 & 105 & 186 & 242 \\
\hline
\end{tabular}

The greatest magnetic activity is observed when the LS consumption is $0.7 \mathrm{~g} \mathrm{LS} / \mathrm{g} \mathrm{Fe}$ in the investigated temperature range. At the same time, as the synthesis temperature increases, the magnetic activity increases over the entire range of LS expenditure.

The magnetic properties of MC were studied using the magnetic granulometry method on samples synthesized at the optimal LS consumption $(0.7 \mathrm{~g} \mathrm{LS} / \mathrm{g} \mathrm{Fe})$ or without LS to assess their role. In order to do that, hot $\left(70 \ldots 80^{\circ} \mathrm{C}\right)$ solutions were mixed in a glass beaker: $50 \mathrm{~mL}$ of ferrous sulfate $(8.75 \mathrm{~g})$ solution, $50 \mathrm{~mL}$ of sodium LS $(2.24 \mathrm{~g})$ solution or $50 \mathrm{~mL}$ of hot water, with $50 \mathrm{~mL}$ of a solution of potassium chromate $(2 \mathrm{~g}, 10.3 \mathrm{mmol}$ of $\mathrm{Cr}$ ) or potassium dichromate $(1.52 \mathrm{~g}, 10.3 \mathrm{mmol}$ of $\mathrm{Cr})$. Condensation was carried out by $60 \mathrm{~mL}$ of $2 \mathrm{M}$ sodium hydroxide solution. The resulting suspension was centrifuged for $5 \mathrm{~min}$ at $5000 \mathrm{~min}^{-1}$. The precipitate was washed by decantation to neutral medium, and dried to constant weight. The results of determining the magnetic characteristics are given in Table 2.

Table 2: Characteristics of magnetic properties

\begin{tabular}{c|cc|c|c|c}
\hline \multirow{2}{*}{ Sample } & \multicolumn{2}{|c|}{ Reagent consumption, g } & \multirow{2}{\sigma_{\mathrm{r}}}{} & $\begin{array}{c}\sigma_{\mathrm{s}} \\
(\mathrm{emu} / \mathrm{g})\end{array}$ & $\begin{array}{c}\mathrm{H}_{\mathrm{c}} \\
(\mathrm{O})\end{array}$ \\
\cline { 2 - 4 } 1 (without LS) & 2 & - & 1.4 & 18.8 & 36.0 \\
2 & 2 & - & 1.7 & 13.0 & 61.0 \\
\hline 3 (without LS) & - & 1.52 & 1.8 & 18.2 & 41.0 \\
4 & - & 1.52 & 2.1 & 16.9 & 60.0 \\
\hline $\mathrm{FeSO}_{4}$ consumption was $8.75 \mathrm{~g}$ &
\end{tabular}

$\mathrm{FeSO}_{4}$ consumption was $8.75 \mathrm{~g}$

Thus, the synthesized MC samples are ferrimagnets. The use of LS allows to achieve a higher magnetic activity and coercive force MC. To carry out the redox reaction, both chromate and potassium dichromate can be used.

\section{Conclusion}

It has been shown experimentally that the interaction of iron(II) cations with chromate-anions passes with the formation of an water soluble intermediate without redox transformations in a weakly acidic medium ( $\mathrm{pH} \mathrm{3.4).} \mathrm{The} \mathrm{ratio} \mathrm{of} \mathrm{chromate-ions} \mathrm{and}$ $\mathrm{Fe}(\mathrm{II})$ cations in the intermediate is $1: 2.33$. The intermediate solution is stable for a long time. MC is formed when the solution is alkalinized. Synthesized MC samples are ferrimagnets. The use of LS and the synthesis with heating can achieve a higher magnetic activity of MC. The LS consumption of $0.7 \mathrm{~g} \mathrm{LS} / \mathrm{g}$ Fe is optimal.

\section{Acknowledgement}

The work was performed using the instrumentation of Core Facility Center "Arktika" of Northern (Arctic) Federal University (project RFMEFI59417X0013).

\section{References}

[1] Dermentzis K, Christoforidis A \& Valsamidou E (2010) Removal of nickel, copper, zinc and chromium from synthetic and industrial wastewater by electrocoagulation. International Journal of Environmental Sciences 1, 697-710.

[2] Pare S, Persson I, Guel B \& Lundberg D (2013) Trivalent Chromium removal from Aqueous solution using Raw Natural Mixed Clay from BURKINA FASO. International Journal of Environmental Sciences 2, 30-37.

[3] Cohen RR \& Ozawa T (2013) Microbial Sulfate Reduction and Biogeochemistry of Arsenic and Chromium Oxyanions in Anaerobic Bioreactors. Water, Air, and Soil Pollution 224, Article number 1732.

[4] Gawande MB, Brancoa PS \& Varma RS (2013) Nano-magnetite $\left(\mathrm{Fe}_{3} \mathrm{O}_{4}\right)$ as a support for recyclable catalysts in the development of sustainable methodologies. Chemical Society Reviews 42, 33713393.

[5] Kempe H \& Kempe M (2010) The use of magnetite nanoparticles for implant-assisted magnetic drug targeting in thrombolytic therapy. Biomaterials 31, 9499-9510.

[6] Mendoza ME, Donado F, Silva R \& Perez MA (2005) Magnetite microcrystals for magneto-rheological fluids. Journal of Physics and Chemistry of Solids 66, 927-931.

[7] Bocanegra-Dias A, Mohallem NDS \& Sinisterra RD (2003) Preparation of a ferrofluid using cyclodextrin and magnetite. Journal of the Brazilian Chemical Society 14, 936-941.

[8] Breitzer J \& Lisensky G (1999) Synthesis of aqueous ferrofluid. Journal of Chemical Education 76, 943-948.

[9] Qiu L \& Snaglewski AP (2015) Lithium adsorption on magnetite, lepidocrocite, and maghemite at elevated temperatures. Nuclear Science and Engineering. 179, 199-210.

[10] Ishaq M, Sultan S, Ahmad I, Ullah H, Yaseen M \& Amir A (2015) Adsorptive desulfurization of model oil using untreated, acid activated and magnetite nanoparticle loaded bentonite as adsorbent. Journal of Saudi Chemical Society 21, 143-151.

[11] Basualto C, Gaete J, Molina L, Valenzuela F, Yañez C \& Marco JF (2015) Lanthanide sorbent based on magnetite nanoparticles functionalized with organophosphorus extractants. Science and Technology of Advanced Materials 16, Article number 035010.

[12] Sun X, Sun K \& Liang Y (2015) Hydrothermal synthesis of magnetite: investigation of influence of aging time and mechanism. $\mathrm{Mi}$ cro \& Nano Letters 10, 99-104.

[13] Hyeon T (2003) Chemical synthesis of magnetic nanoparticles. Chemical Communications 8, 927-934.

[14] Shen L, Laibinis PE \& Hatton TA (1998) Bilayer Surfactant Stabilized Magnetic Fluids: Synthesis and Interactions at Interfaces. Langmuir 15, 447-453.

[15] Massart R (1981) Preparation of aqueous magnetic liquids in alkaline and acidic media. IEEE Transactions on Magnetics 17, $1247-$ 1248.

[16] Subbotin KA, Mikhailichenko AI \& Nefedova NV (2000) Effect of synthesis conditions on magnetic properties of magnetite. Russian Journal of Applied Chemistry 73, 1671-1675.

[17] Hosseini-Monfared H, Parchegani F \& Alavi S (2015) Carboxylic acid effects on the size and catalytic activity of magnetite nanoparticles. Journal of Colloid and Interface Science 437, 1-9.

[18] Sarkanen KV and Ludwig CH (1971) Lignins: Occurrence, formation, structure and reactions, Eds., John Wiley \& Sons, Inc., New York, 916 p.

[19] Babkin I, Brovko O, Iakovlev M, \& Khabarov Yu (2013) Ferrofluid Synthesis Using Nitrosated Lignosulfonates. Industrial \& Engineering Chemistry Research 52, 7746-7751.

[20] Chernavskii PA, Pankina GV, Lunin VV (2011) Magnetometric methods of investigation of supported catalysts. Russian Chemical Reviews 80, 579-604.

[21] Lide D.R. CRC Handbook of Chemistry and Physics. 88th. Edition. Boca Raton: CRC Press, Taylor \& Francis. 2007. 2640 p.

[22] Khabarov YuG, Kuzyakov NYu, Veshnyakov VA, Malkov AV, Shkaeva NV \& Pankina GV (2017) Synthesis of a Magnetoactive Compound by the Interaction of Iron(II) Sulfate with Potassium Chromate. Russian Journal of Inorganic Chemistry 62, 230-234. 